\title{
Low-density PMMA/MAM nanocellular polymers using low MAM contents: Production and characterization
}

\author{
Victoria Bernardo ${ }^{\mathrm{a}, *}$, Judith Martin-de Leon ${ }^{\mathrm{a}}$, Javier Pinto ${ }^{\mathrm{b}}$, Tiziano Catelani ${ }^{\mathrm{c}}$, \\ Athanassia Athanassiou ${ }^{\mathrm{b}}$, Miguel Angel Rodriguez-Perez ${ }^{\mathrm{a}}$ \\ ${ }^{a}$ Cellular Materials Laboratory (CellMat), Condensed Matter Physics Department, University of Valladolid, Campus Miguel Delibes, Paseo de Belén $n^{\circ} 7,47011$, Valladolid, \\ Spain \\ ${ }^{\mathrm{b}}$ Smart Materials, Istituto Italiano di Tecnologia, Via Morego 30, 16163, Genova, Italy \\ ${ }^{\mathrm{c}}$ Electron Microscopy Facility, Istituto Italiano di Tecnologia, Via Morego 30, 16163, Genova, Italy
}

\section{H I G H L I G H T S}

- Low-density nanocellular polymers based on PMMA/MAM blends are produced.

- Low MAM copolymer contents, as low as $0.1 \mathrm{wt} \%$, are used to produce such materials.

- The physical mechanisms that allow this reduction of the density are discussed.

\section{A R T I C L E I N F O}

\section{Keywords:}

Nanocellular polymer

Nanocellular foam

Gas dissolution foaming

Block copolymer

Nanostructuration

PMMA

MAM

\begin{abstract}
A B S T R A C T
Low-density nanocellular polymers are required to take advantage of the full potential of these materials as high efficient thermal insulators. However, their production is still a challenging task. One promising approach is the use of nanostructured polymer blends of poly(methyl methacrylate) (PMMA) and a block copolymer poly(methyl methacrylate)-poly(butyl acrylate)-poly(methyl methacrylate) (MAM), which are useful for promoting nucleation but seem to present a severe drawback, as apparently avoid low relative densities. In this work, new strategies to overcome this limitation and produce low-density nanocellular materials based on these blends are investigated. First, the effect of very low amounts of the MAM copolymer is analysed. It is detected that nanostructuration can be prevented using low copolymer contents, but nucleation is still enhanced as a result of the copolymer molecules with high $\mathrm{CO}_{2}$ affinity dispersed in the matrix, so nanocellular polymers are obtained using very low percentages of the copolymer. Second, the influence of the foaming temperature is studied. Results show that for systems in which there is not a clear nanostructuration, cells can grow more freely and smaller relative densities can be achieved.

For these studies, blends of PMMA with MAM with copolymer contents from $10 \mathrm{wt} \%$ and as low as $0.1 \mathrm{wt} \%$ are used. For the first time, the production strategies proposed in this work have allowed obtaining low density (relative density 0.23 ) nanocellular polymers based on PMMA/MAM blends.
\end{abstract}

\section{Introduction}

Efficient energy use is one of the main concerns of nowadays society. All sectors are in need of efficient management of the energy use, but the major challenge from the next decades lies in buildings, according to the European Commission [1]. More than one-third of global energy consumption is used in buildings, and from this energy, more than $50 \%$ is needed to heat indoor spaces [2]. Most heat is lost through walls, roofs, and floors. Therefore, proper insulation is required to reduce the losses and therefore the energy consumptions. With improved thermal insulators not only would money be saved, but also $\mathrm{CO}_{2}$ emissions associated with energy production would be significantly reduced.

Therefore, finding new and better materials with enhanced insulation properties becomes a mandatory task. Current trends to reduce the thermal conductivity of insulating materials are to replace the air inside them with vacuum [3] or to reduce the pore size below the mean free path of air molecules $[4,5]$, that is, producing nanocellular materials.

\footnotetext{
${ }^{*}$ Corresponding author.

E-mail address: vbernardo@fmc.uva.es (V. Bernardo).
} 
Nanocellular materials, characterized by cell sizes in the range of tens to hundreds of nanometers, present a unique combination of properties [5-10], and in particular a reduced thermal conductivity thanks to the Knudsen effect $[5,11,12]$. To fully take advantage of this effect, low-density nanocellular materials are required [13]. Nevertheless, the production of such low-density materials is still not well established.

Several attempts to produce low-density nanocellular polymers have been carried out using the so-called gas dissolution foaming technique [14-17]. Up to date, the most promising results have been obtained using poly(methyl methacrylate), PMMA, as the polymer matrix. Guo et al. [18] used a low temperature set up $\left(-20^{\circ} \mathrm{C}\right)$ to produce nanocellular PMMA with cell sizes of $235 \mathrm{~nm}$ and relative densities of 0.14. In the work of Martin-de Leon [19], high saturation pressure (31 MPa) was needed to obtain a cellular PMMA with a relative density of 0.24 , keeping the cell size in the nanoscale $(216 \mathrm{~nm})$. They also established a procedure to tune the relative density by changing the foaming temperature. In the work of Costeux et al. [20], the effect of the molecular structure of some PMMA copolymers was investigated, achieving relative densities around 0.2 and cell sizes below $400 \mathrm{~nm}$. A high saturation pressure (30 MPa) was also required in their work. As a rule, the production of nanocellular polymers using pure polymers demands extreme processing conditions, such as high pressures or low temperatures (under $0{ }^{\circ} \mathrm{C}$ ) $[14,15,17,21]$. Both approaches are difficult to scale-up to the industrial production, due to the technical requirements and costs associated to work at these conditions. For this reason, the use of nucleating species has become a common strategy to reach high nucleation densities at mild processing conditions that could be easier and cost-effective to use in the industrial scale.

The first approach is the use of nanoparticles as nucleating agents to favor nucleation [22,23]. Costeux et al. [24] take advantage of heterogeneous nucleation for the production of low relative density $(0.15)$ nanocellular PMMA (cell size of $100 \mathrm{~nm}$ ). They used silica nanoparticles contents below $0.5 \mathrm{wt} \%$ to achieve this result, but the saturation pressure required was still high (30 MPa). Bernardo et al. [25] used needlelike sepiolites to obtain bimodal structures, with both micro and nanocells, in PMMA. The relative densities were between 0.21 and 0.28 and the cell size between 300 and $500 \mathrm{~nm}$ for sepiolite contents in the range from 0.5 to $1.5 \mathrm{wt} \%$. They showed that it was possible to produce these materials using not demanding processing conditions (soaking at $10 \mathrm{MPa}$ and room temperature).

On the other hand, nanostructured polymer blends with $\mathrm{CO}_{2}$-philic domains can be used as nucleating species [26,27]. Nevertheless, reducing the relative density under 0.3 using this approach is still a challenge not overcome. Pinto et al. [28-30] worked with blends of PMMA and poly(methyl methacrylate)-poly(butyl acrylate)-poly(methyl methacrylate) (MAM) with contents of MAM of $5 \mathrm{wt} \%, 10 \mathrm{wt} \%$, $20 \mathrm{wt} \%$ and higher. They obtained cell sizes below $200 \mathrm{~nm}$ at $10 \mathrm{MPa}$ of saturation pressure with a $10 \mathrm{wt} \%$ of MAM, but with relative densities above 0.4. Bernardo et al. [31] investigated the influence of the MAM molecular weight in the production of PMMA/MAM nanocellular polymers. They showed that reducing the MAM molecular weight allows decreasing the relative density up to 0.37 , the cell size being around $200 \mathrm{~nm}$. Forest and coworkers [32] analyzed the effect of changing the copolymer content in the structure of PMMA/MAM-based nanocellular polymers. They found that higher copolymer contents (up to $20 \mathrm{wt} \%$ ) led to larger cell nucleation densities, but also higher relative densities. In that work, MAM contents up to a $1 \mathrm{wt} \%$ were used, and nanocellular polymers of around $150 \mathrm{~nm}$ were obtained using a $1 \mathrm{wt} \%$ of MAM, but with a relative density of 0.42 . Low saturation pressure $(3.2 \mathrm{MPa})$ and low saturation temperature $\left(0{ }^{\circ} \mathrm{C}\right)$, were required to obtain those materials.

In all the previously mentioned works, copolymer contents of at least $1 \mathrm{wt} \%$ were necessary to achieve a nanocellular structure, whereas the densities obtained were far away from the results obtained using pure polymers or nanoparticles as a nucleating agent. In an own previous work [31] we proposed that the presence of the micelles is a limiting parameter in the production of low density nanocellular materials based on PMMA/MAM blends. Besides, these copolymers are usually expensive and not easily available, and due to this, the high contents needed complicate its use as possible nucleating agents on the industrial production of nanocellular polymers.

In this work, the effect of the copolymer content in the production of PMMA/MAM nanocellular polymers has been explored as a strategy to reduce the relative density of such materials. Contents below $10 \mathrm{wt} \%$ were analyzed. In particular, very low MAM contents $(0.1 \mathrm{wt} \%$ and $0.5 \mathrm{wt} \%$ ) have been used, allowing to obtain nanocellular materials based on PMMA-MAM with relative densities below 0.3 for the first time.

\section{Experimental}

\subsection{Materials}

PMMA V 825T was kindly supplied by ALTUGLAS ${ }^{\bullet}$ International in the form of pellets. This PMMA presents a melt flow index (MFI) of $1.8 \mathrm{~g} / 10 \mathrm{~min}$ (measured at $230^{\circ} \mathrm{C}$ and $2.16 \mathrm{~kg}$ ), a density ( $\rho$ ) of $1.19 \mathrm{~g} /$ $\mathrm{cm}^{3}$ and a glass transition temperature $\left(\mathrm{T}_{\mathrm{g}}\right)$ of $114.5^{\circ} \mathrm{C}$, measured by DSC. The molecular weight of this PMMA is $M_{n}=43 \mathrm{~kg} / \mathrm{mol}$ and $\mathrm{M}_{\mathrm{w}}=83 \mathrm{~kg} / \mathrm{mol}$ as determined by GPC.

MAM block copolymers were kindly supplied by Arkema Company (France). Three MAM copolymers with different molecular weights were used in this study. The three copolymers have roughly a $50 \mathrm{wt} \%$ of the soft block, poly(butyl acrylate) (PBA). Commercial names of these copolymers are Nanostrength M51 (low molecular weight), M52 (medium molecular weight) and M53 (high molecular weight). Table 1 summarizes the main characteristics of these copolymers. MFI was measured at $160^{\circ} \mathrm{C}$ and $10 \mathrm{~kg}$, and molecular weight was determined using GPC measurements. PBA fraction was determined from NMR measurements. $\mathrm{T}_{\mathrm{g}}$ of the PBA phase was determined by DSC. More details about the characterization of the copolymers can be found elsewhere [31].

Finally, medical grade carbon dioxide $\left(\mathrm{CO}_{2}\right)$ (99.9\% purity) was used as the blowing agent for the gas dissolution foaming experiments.

\subsection{Solid blends production}

PMMA/MAM blends with different MAM contents were compounded using a twin-screw extruder model COLLIN TEACH-LINE ZK 25T, with L/D of 24 and screw diameter of $25 \mathrm{~mm}$. Before compounding, PMMA and MAM were dried in vacuum at $50^{\circ} \mathrm{C}$ for $12 \mathrm{~h}$. Then, the blends with the appropriate proportions were extruded with a temperature profile from $160^{\circ} \mathrm{C}$ to $200^{\circ} \mathrm{C}$ (in the die), increasing in

Table 1

Characteristics of the MAM block copolymers used in this work.

\begin{tabular}{|c|c|c|c|c|c|c|}
\hline ID & Description & $\mathrm{M}_{\mathrm{n}}(\mathrm{kg} / \mathrm{mol})$ & $\mathrm{M}_{\mathrm{w}}(\mathrm{kg} / \mathrm{mol})$ & MFI (g/10 min) & $\mathrm{T}_{\mathrm{g}, \mathrm{PBA}}\left({ }^{\circ} \mathrm{C}\right)$ & PBA (wt $\%)$ \\
\hline $\mathrm{L}$ & Low molecular weight & 25 & 46 & $84 \pm 9$ & -26.2 & 48 \\
\hline M & Medium molecular weight & 44 & 75 & $4 \pm 1$ & -34.9 & 52 \\
\hline $\mathrm{H}$ & High molecular weight & 82 & 128 & $0.208 \pm 0.003$ & -39.8 & 54 \\
\hline
\end{tabular}


Table 2

Formulations used in this work.

\begin{tabular}{lllllll}
\hline \multicolumn{2}{l}{ MAM content } & & & & & \\
\hline 0.1 wt $\%$ & & & $0.5 \mathrm{wt} \%$ & $1 \mathrm{wt} \%$ & $5 \mathrm{wt} \%$ & $10 \%$ \\
\hline \multirow{2}{*}{ Type of MAM } & $\mathrm{L}$ & $0.1 \%-\mathrm{L}$ & $0.5 \%-\mathrm{L}$ & $1 \%-\mathrm{L}$ & $5 \%-\mathrm{L}$ & $10 \%-\mathrm{L}$ \\
& $\mathrm{M}$ & $0.1 \%-\mathrm{M}$ & $0.5 \%-\mathrm{M}$ & $1 \%-\mathrm{M}$ & $5 \%-\mathrm{M}$ & $10 \%-\mathrm{M}$ \\
& $\mathrm{H}$ & $0.1 \%-\mathrm{H}$ & $0.5 \%-\mathrm{H}$ & $1 \%-\mathrm{H}$ & $5 \%-\mathrm{H}$ & $10 \%-\mathrm{H}$ \\
\hline
\end{tabular}

intervals of $10^{\circ} \mathrm{C}$, and at a screw speed of $40 \mathrm{rpm}$. The produced blends were cooled in a water bath and pelletized. After drying for $2 \mathrm{~h}$ in a vacuum oven at $50{ }^{\circ} \mathrm{C}$, the materials were extruded again under the same conditions. Homogeneous and transparent blends were obtained after this process. Blends with five different MAM contents, from $0.1 \mathrm{wt}$ $\%$ to $10 \mathrm{wt} \%$, were produced. Table 2 summarizes the materials produced in this work.

Solid precursors of these blends were prepared by compression molding using a hot plate press provided by Remtex. Solid prisms of $155 \times 75 \times 4 \mathrm{~mm}^{3}$ were produced. First, all materials were dried in a vacuum oven at $50^{\circ} \mathrm{C}$ overnight. Then, the material was first softened at $250^{\circ} \mathrm{C}$ without applying pressure for $8.5 \mathrm{~min}$ and then compacted under constant pressure of $1.7 \mathrm{MPa}$ for another minute. Finally, the samples were cooled down at room temperature on the cold plates under the same pressure. Samples of $20 \times 10 \times 4 \mathrm{~mm}^{3}$ were cut from the solid prisms for the foaming experiments.

Neat PMMA was processed under the same conditions (both by extrusion and compression molding) for comparison.

\subsection{Gas dissolution foaming experiments}

Foaming experiments were performed in a high-pressure vessel (model PARR 4681) provided by Parr Instruments Company with a capacity of $1 \mathrm{~L}$, capable of operating at a maximum temperature of $350{ }^{\circ} \mathrm{C}$ and a maximum pressure of $41 \mathrm{MPa}$. Pressure is set to the desired value with an accurate pressure pump controller (model SFT-10) provided by Supercritical Fluid Technologies Inc. The temperature is fixed with a clamp heater of $1200 \mathrm{~W}$, controlled via a CAL 3300 temperature controller. Foaming experiments were performed using a two-step foaming process [33]. Samples were firstly introduced in the pressure vessel under $10 \mathrm{MPa}$ of $\mathrm{CO}_{2}$ pressure for the saturation stage. Saturation temperature was equal to $25^{\circ} \mathrm{C}$ and saturation time was $20 \mathrm{~h}$, as this time was proved to be enough to achieve full saturation of $\mathrm{CO}_{2}$ in PMMA at the conditions under study. After saturation, the pressure was abruptly released (pressure drop rate: $15 \mathrm{MPa} / \mathrm{s}$ ), and the samples were immersed in a thermal bath at the desired temperature for the foaming stage. The time between the release of pressure and the sample immersion in the thermal baths was $3.5 \mathrm{~min}$. The sorption process depends on pressure and temperature. At the conditions used in this work $\left(10 \mathrm{MPa}\right.$ and $25^{\circ} \mathrm{C}$ ) solubility of $\mathrm{CO}_{2}$ in PMMA is around $24 \mathrm{wt} \%$. This value was calculated by weighting the sample before and immediately after the saturation process. For the MAM copolymers, the solubility was estimated by weighting samples with $10 \mathrm{wt} \%$ of MAM and calculating the amount absorbed by the copolymer in the blend. It is observed than MAM presents a higher $\mathrm{CO}_{2}$ affinity that PMMA and can absorb approximately $38 \mathrm{wt} \%$ at $10 \mathrm{MPa}$ and $25^{\circ} \mathrm{C}$. See Supplementary Information for details about the procedure to measure the solubility.

The influence of the amount of block copolymer was evaluated by fixing the foaming temperature at $80{ }^{\circ} \mathrm{C}$. Then, the effect of the foaming temperature was analyzed by using two additional foaming temperatures: 60 and $100^{\circ} \mathrm{C}$. Foaming time was $1.5 \mathrm{~min}$ for all the experiments. Under these saturation conditions $\left(25^{\circ} \mathrm{C}\right.$ and $10 \mathrm{MPa}$ ) the effective glass transition temperature of PMMA after gas absorption is below room temperature [30], and thus samples start to expand immediately after the depressurization. However, the largest expansion occurs in the thermal baths.

\subsection{Characterization}

\subsubsection{Nanostructuration of the blends}

Morphology of the solid PMMA/MAM blends was analyzed using transmission electron microscopy (TEM). Each material was cut in ultrathin slices (with a thickness of approximately $80-90 \mathrm{~nm}$ ) using a Leica EM UC6 Ultramicrotome. The samples were cut in cryogenic conditions, cooling down the environment and the sample holder at least at $-60{ }^{\circ} \mathrm{C}$, using a specific cryo-system Leica EM FC6 and a specific diamond knife for a low-temperature cut. This step was necessary due to the soft behavior of the polymer. Slices were collected and laid down onto a 200 mesh formvar/carbon-coated copper TEM grids.

Transmission electron microscopy (TEM) images were collected with a Jeol JEM 1011 (Jeol, Japan) electron microscope (Electron Microscopy Facility, Istituto Italiano di Tecnologia, Genova, Italy). The acceleration voltage used was $100 \mathrm{kV}$ and recorded with an $11 \mathrm{Mp}$ fiber optical charge-coupled device (CCD) camera (Gatan Orius SC-1000).

TEM images were used to analyze the nanostructuration found in the solid blends. Volumetric micelle density was calculated by dividing the number of micelles in a TEM image by the volume (area of the image times the thickness of the sample (around $80 \mathrm{~nm}$ )).

From the micelle density $\left(n_{\text {mic }}\right.$ ), the aggregation number $N_{c}$ (number of copolymer molecules per micelle) was estimated theoretically using equation (1) [34], where $w$ is the amount of copolymer in weight percent, $N_{a v}$ is the Avogadro's number, $\rho$ is the density of the blend and $M_{n}$ is the molecular weight of the copolymer.

$n_{\text {mic }}=\frac{w N_{a v} \rho}{M_{n} N_{c}}$

\subsubsection{Density}

The density of the solid samples was measured with a gas pycnometer (model AccuPyc II 1340, Micromeritics) and the density of the cellular materials was determined with the water-displacement method based on Archimedes' principle. For this purpose, a density determination kit for an AT261 Mettler-Toledo balance was used. Before measuring the density, the solid skin of these foamed samples was removed out with a polisher (model LaboPOl2-LaboForce3, Struers) by removing at least $200 \mu \mathrm{m}$ of each side. Relative density $\left(\rho_{r}\right)$ has been calculated as the ratio between the cellular material density $\left(\rho_{f}\right)$ and the density of the solid polymer blend $\left(\rho_{s}\right)$.

\subsubsection{Cellular structure}

The cellular structure of the samples was analyzed using an ESEM, Environmental Scanning Electron Microscope (Quanta 200 FEG). For the visualization, samples were fractured after cooling in liquid nitrogen. Also, they were coated with gold using a sputter coater (model SCD 005, Balzers Union). A tool based on the software ImageJ/FIJI [35] has been used to quantify the structural parameters that characterize the cellular structure. First, the average cell size $(\phi)$ has been measured, and the standard deviation coefficient of the cell size distribution (SD) has been obtained. Cell density $\left(N_{v}\right)$ and cell nucleation density $\left(N_{0}\right)$ were determined using Kumar's theoretical approximation [36] according to equations (2) and (3), respectively, where $n$ is the number of cells in the image and $A$ is the area of the image. More than 200 cells of different areas of each cellular material were analysed.

$N_{v}=\left[\frac{n}{A}\right]^{3 / 2}$

$N_{0}=\frac{N_{v}}{\rho_{r}}$

Cell wall thickness of the cellular materials was measured directly from the micrographs. More than fifty cell walls were measured per material system. Finally, the fraction of mass in the struts was determined using the local thickness analysis of Image J/FIJI (details can 

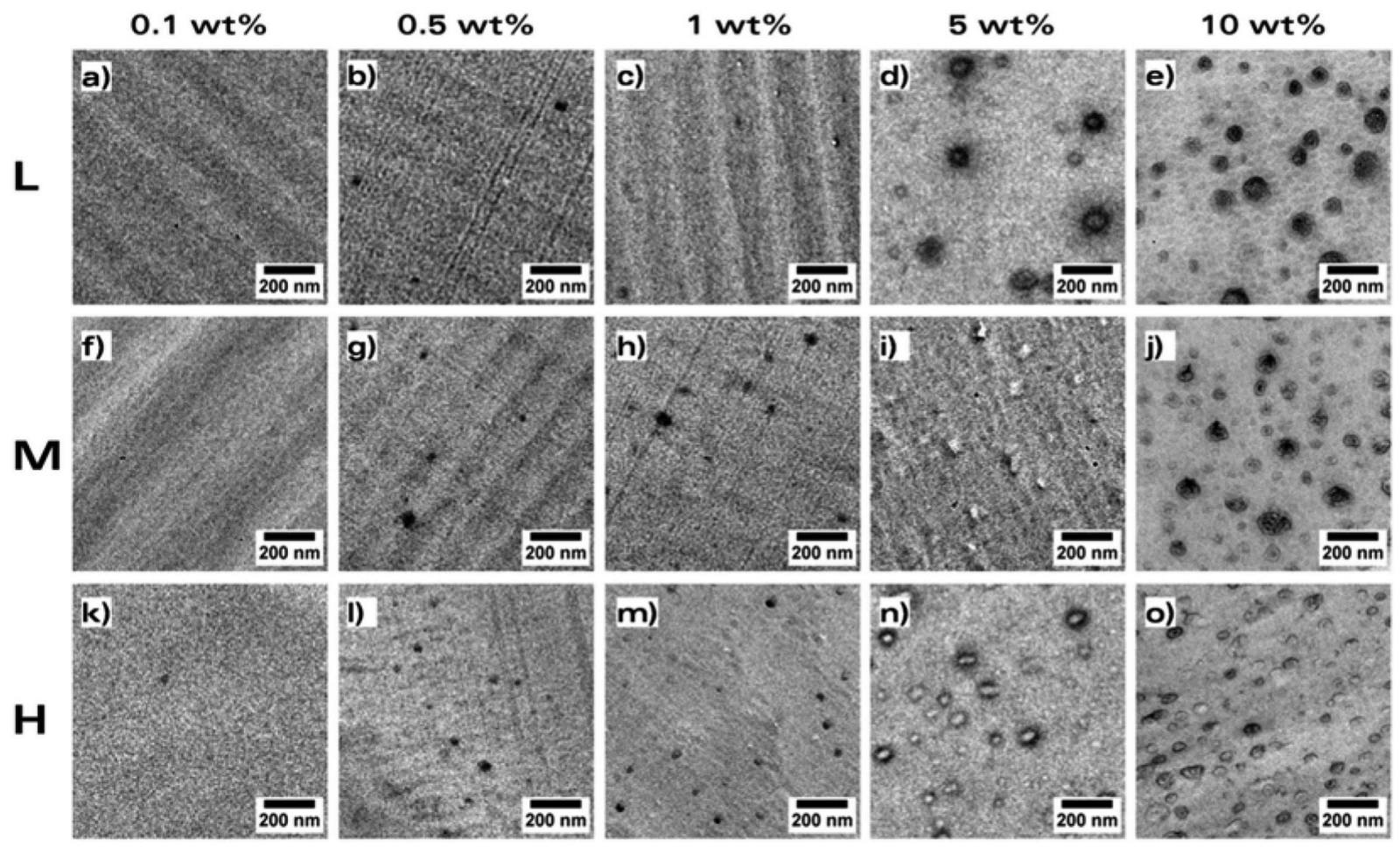

Fig. 1. TEM images showing the nanostructuration (black spots) of the PMMA/MAM blends: a) $0.1 \%-\mathrm{L}, \mathrm{b}$ ) $0.5 \%-\mathrm{L}, \mathrm{c}$ ) $1 \%-\mathrm{L}, \mathrm{d}$ ) $5 \%-\mathrm{L}$, e) $10 \%-\mathrm{L}, \mathrm{f})$ 0.1\%-M, g) $0.5 \%-\mathrm{M}$, h) $1 \%-\mathrm{M}$, i) $5 \%-\mathrm{M}$, j) $10 \%-\mathrm{M}$, k) $0.1 \%-\mathrm{H}$, l) $0.5 \%-\mathrm{H}, \mathrm{m}) 1 \%-\mathrm{H}, \mathrm{n}) 5 \%-\mathrm{H}$ and o) $10 \%-\mathrm{M}$.

be found elsewhere [19]).

\section{Results}

\subsection{Nanostructuration of the blends}

Fig. 1 shows the TEM images of the solid blends for all the contents of MAM and the three grades of MAM. It should be noted that the nanostructuration observed on these samples is obtained from a nonequilibrium process as the extrusion is [31]. The micelle nanostructuration is detected at contents from $10 \mathrm{wt} \%$ down to $0.5 \mathrm{wt} \%$. It is observed that micelle density decreases in one order of magnitude (from $10^{14}$ nuclei $/ \mathrm{cm}^{3}$ to $10^{13}$ nuclei/ $\mathrm{cm}^{3}$ ) when MAM content is reduced from 10 to $0.5 \mathrm{wt} \%$ (Table 3). This effect is observed for the three different copolymers. However, at a content of $0.1 \mathrm{wt} \%$, there is not an evident nanostructuration. For the blends $0.1 \%-\mathrm{M}$ and $0.1 \%-\mathrm{H}$ some dispersed micelles were detected and quantified for the analysis of the micelle density Table 3), whereas for the blend 0.1\%-L it was not possible to perform such an analysis because micelles were not detected. It is also observed that higher MAM molecular weights lead to higher micelle densities, as it was already reported and explained in own previous work [31].

We hypothesized that formation of the micelles is a consequence of two processes [31]: dispersion during the extrusion and self-assembly of the MAM molecules in the domains formed by the extrusion. That is, during the extrusion process, MAM will be dispersed forming MAM-rich regions. This dispersion is mainly controlled by the relative viscosities of the matrix and the copolymer, so the different trends found for the three copolymers are related to their different viscosities [31]. In the domains formed during the extrusion, if the number of copolymer molecules is high enough, self-assembly takes place, resulting in micelles. In order to evaluate the number of copolymer molecules involved in the formation of the micelles, it is possible to estimate theoretically the aggregation numbers using equation (1) and the

Table 3

Nanostructure characteristics of PMMA/MAM solid precursors.

\begin{tabular}{|c|c|c|c|}
\hline Sample ID & Micelle density (micelles $/ \mathrm{cm}^{3}$ ) & Predicted aggregation number & MAM distribution on the PMMA matrix \\
\hline $0.1 \%-\mathrm{L}$ & - & - & Mainly dispersed \\
\hline $0.5 \%-\mathrm{L}$ & $(2.4 \pm 0.2) \cdot 10^{13}$ & 5800 & Dispersed and forming micelles \\
\hline $1 \%-\mathrm{L}$ & $(9.0 \pm 3.0) \cdot 10^{13}$ & 3000 & Mainly forming micelles \\
\hline $5 \%-\mathrm{L}$ & $(8.4 \pm 0.1) \cdot 10^{13}$ & 16800 & Mainly forming micelles \\
\hline $10 \%-\mathrm{L}$ & $(2.1 \pm 0.0) \cdot 10^{14}$ & 13400 & Mainly forming micelles \\
\hline $0.1 \%-\mathrm{M}$ & $(1.6 \pm 0.7) \cdot 10^{13}$ & 1000 & Dispersed and forming micelles \\
\hline $0.5 \%-\mathrm{M}$ & $(6.6 \pm 0.1) \cdot 10^{13}$ & 1200 & Dispersed and forming micelles \\
\hline $1 \%-\mathrm{M}$ & $(1.4 \pm 0.5) \cdot 10^{14}$ & 1100 & Mainly forming micelles \\
\hline $5 \%-\mathrm{M}$ & $(1.3 \pm 0.3) \cdot 10^{14}$ & 6000 & Mainly forming micelles \\
\hline $10 \%-\mathrm{M}$ & $(7.3 \pm 0.4) \cdot 10^{14}$ & 2200 & Mainly forming micelles \\
\hline $0.1 \%-\mathrm{H}$ & $(4.0 \pm 2.0) \cdot 10^{12}$ & 2300 & Dispersed and forming micelles \\
\hline $0.5 \%-\mathrm{H}$ & $(8.0 \pm 3.0) \cdot 10^{13}$ & 500 & Dispersed and forming micelles \\
\hline $1 \%-\mathrm{H}$ & $(2.0 \pm 1.0) \cdot 10^{14}$ & 400 & Mainly forming micelles \\
\hline $5 \%-\mathrm{H}$ & $(2.0 \pm 0.2) \cdot 10^{14}$ & 2200 & Mainly forming micelles \\
\hline $10 \%-\mathrm{H}$ & $(7.7 \pm 0.9) \cdot 10^{14}$ & 1100 & Mainly forming micelles \\
\hline
\end{tabular}


$0.1 w t \%$
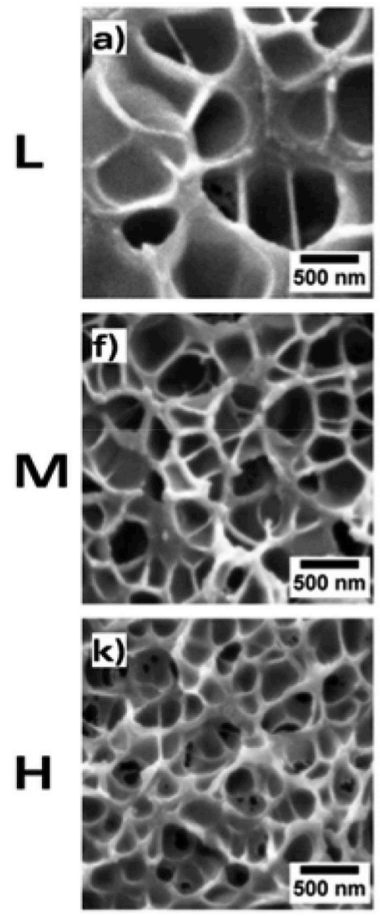

$0.5 \mathrm{wt} \%$
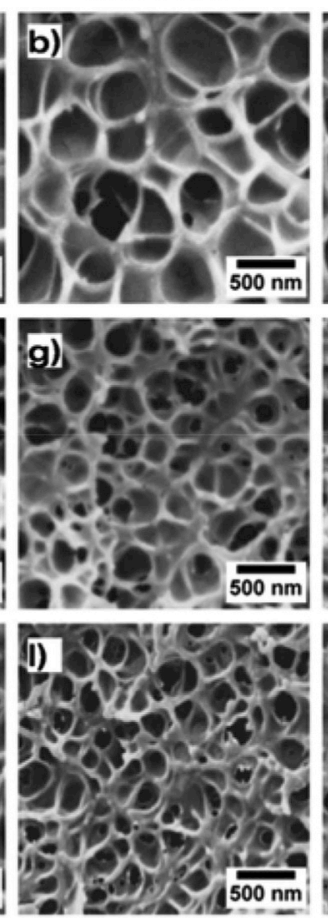

$1 \mathrm{wt} \%$
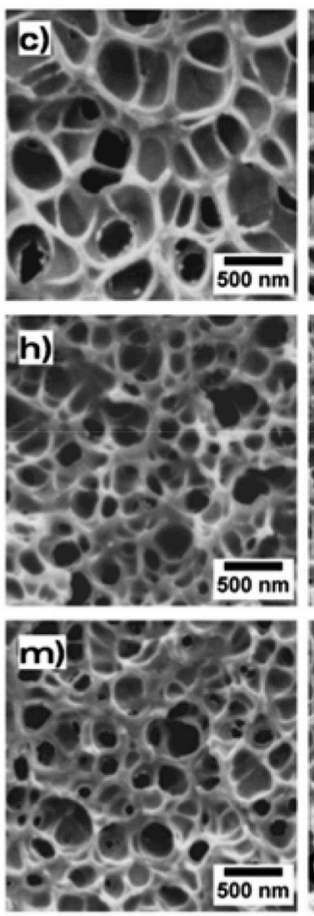

5 wt $\%$
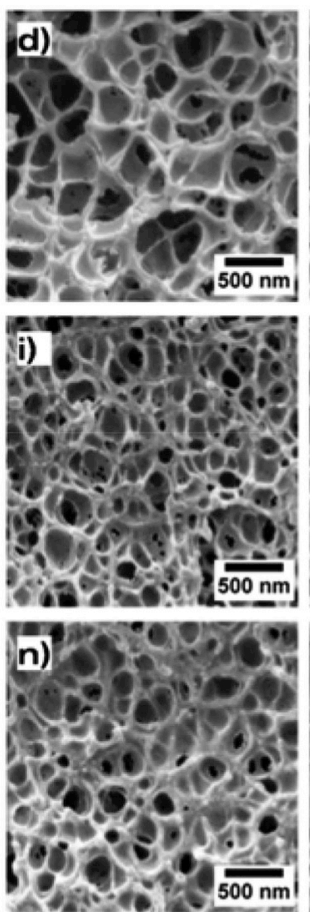

$10 \mathrm{wt} \%$
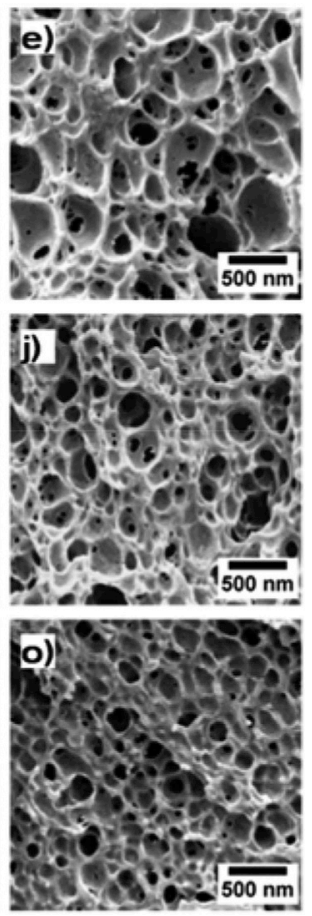

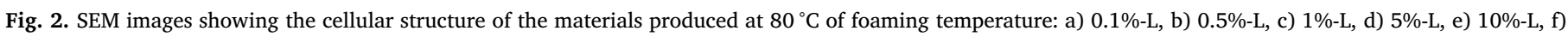
0.1\%-M, g) 0.5\%-M, h) 1\%-M, i) 5\%-M, j) 10\%-M, k) $0.1 \%-\mathrm{H}, 1) 0.5 \%-\mathrm{H}, \mathrm{m}) 1 \%-\mathrm{H}$, n) $5 \%-\mathrm{H}$ and o) $10 \%-\mathrm{H}$.

experimental number of micelles (Table 3). This number is calculated by assuming all the copolymer lies inside the micelles. If this estimation is in agreement with the TEM observation, which shows the number and sizes of the micelles, we can assume the hypothesis is correct. If not, then it is plausible to assume that some of the copolymer is dispersed in the matrix without forming a micelle. From the correlation between the predicted aggregation number and the TEM observations, we can distinguish three levels of distribution of MAM in the PMMA matrix: mainly forming micelles, dispersed and foaming micelles, and mainly dispersed (Table 2).

When MAM content is reduced from $10 \mathrm{wt} \%$ to $5 \mathrm{wt} \%$, a decrease in the micelle density is observed (Table 3), but also micelles look larger (Fig. 1). As micelles are larger at $5 \mathrm{wt} \%$, this means the number of molecules per micelle (i.e., aggregation number) should be higher at $5 \mathrm{wt} \%$ than at $10 \mathrm{wt} \%$ (in agreement with Table 3). Then, MAM is dispersed in bigger regions for $5 \mathrm{wt} \%$ compared to $10 \mathrm{wt} \%$. However, these two contents are of the same order of magnitude, and we can consider both micelle density and aggregation numbers comparable. Pinto and coworkers [30] already showed comparable nanostructures at 5 and $10 \mathrm{wt} \%$ of MAM. For these two contents, the MAM is distributed forming micelles (Table 3).

However, when content is reduced from $5 \mathrm{wt} \%$ to $1 \mathrm{wt} \%$, micelles are smaller, so MAM-rich regions should be smaller. Accordingly, the estimated aggregation number decreases (Table 3). So in the blends with $1 \mathrm{wt} \%$ of MAM the copolymer is also distributed forming micelles.

For lower contents $(0.5 \mathrm{wt} \%$ and $0.1 \mathrm{wt} \%)$, equation (1) predicts very high aggregation numbers, even higher than those obtained at $1 \mathrm{wt}$ $\%$ (for instance, for $0.1 \%-\mathrm{H}$ an aggregation number as high as 2300 is predicted). In those cases, this prediction is contradictory with the TEM observation, in which fewer and smaller micelles are detected (Fig. 1). Therefore, the hypothesis that all of the molecules are forming micelles is not true at these low contents. According to literature, there exists a critical micelle concentration $(\mathrm{cmc})$, that is, a minimum amount of MAM needed to create a micelle [37-39]. Then, it is plausible to assume that at these very low contents $(0.5 \mathrm{wt} \%$ and $0.1 \mathrm{wt} \%)$ some MAM molecules might be dispersed without forming micelles, because the amount of MAM may be below the cmc. This is for sure the case of $0.1 \%-\mathrm{L}$, in which micelles were not detected (and therefore, no aggregation number was estimated). Thus, we conclude that in the blends $0.5 \%-\mathrm{L}, 0.5 \%-\mathrm{M}, 0.5 \%-\mathrm{H}, 0.1 \%-\mathrm{M}$ and $0.1 \%-\mathrm{H}$, the MAM is forming micelles (observed in TEM), but also partially dispersed in the matrix. Finally, in the blend $0.1 \%$-L the MAM is mainly dispersed.

\subsection{Effect of the copolymer content on the cellular structure}

Cellular materials were obtained from the solid PMMA and the PMMA/MAM blends at constant saturation $\left(10 \mathrm{MPa}\right.$ and $\left.25^{\circ} \mathrm{C}\right)$ and foaming $\left(80^{\circ} \mathrm{C}\right.$ and $\left.1.5 \mathrm{~min}\right)$ conditions. Fig. 2 shows the cellular structure of the different samples. Under these conditions, the pure PMMA shows a microcellular structure [31] (see Supplementary Information for details about the structure of the microcellular PMMA). Three main conclusions can be extracted from the SEM micrographs of Fig. 2. First, most of the PMMA/MAM blends produce nanocellular structures. Only the material $0.1 \%$-L shows cells larger than $500 \mathrm{~nm}$. Second, reducing the amount of MAM increases the cell size. Third and last, the molecular weight of the MAM also plays an important role, the cell sizes of the materials based on the copolymer L being sharply larger than the rest, as already proved for the materials with a content of $10 \mathrm{wt}$ $\%$ [31].

The analysis in deep detail of the cellular structure of these cellular materials is shown in Fig. 3. On the one hand, Fig. 3a shows the cell nucleation density as a function of the MAM content. It decreases as MAM content decreases. From the micelle density analysis, this result was expected, as micelle density controls nucleation in nanostructured polymer blends $[26,27,30]$ and it was found to follow the same trend (Table 3). There is a reasonable correlation between the micelle density and the cell nucleation density, except for the very low MAM contents $(0.5 \mathrm{wt} \%$ and $0.1 \mathrm{wt} \%)$. For these systems, the nucleation density is much higher than the micelle density, and also greater than that of the pure PMMA (see Table S2 and Figure S3 in the Supplementary Information). Therefore, the nucleation cannot be merely explained as a consequence of nucleation in the micelles, as in the systems with high 
a)

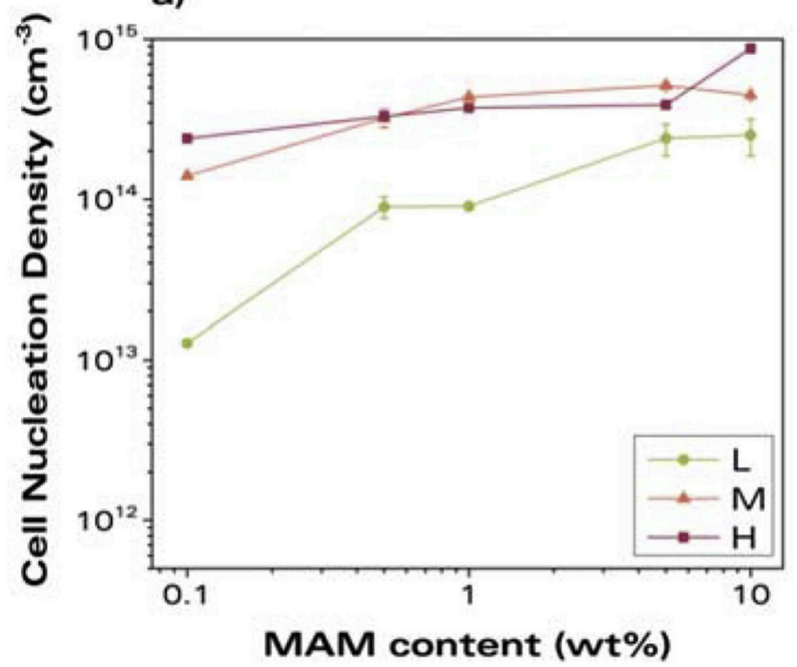

b)

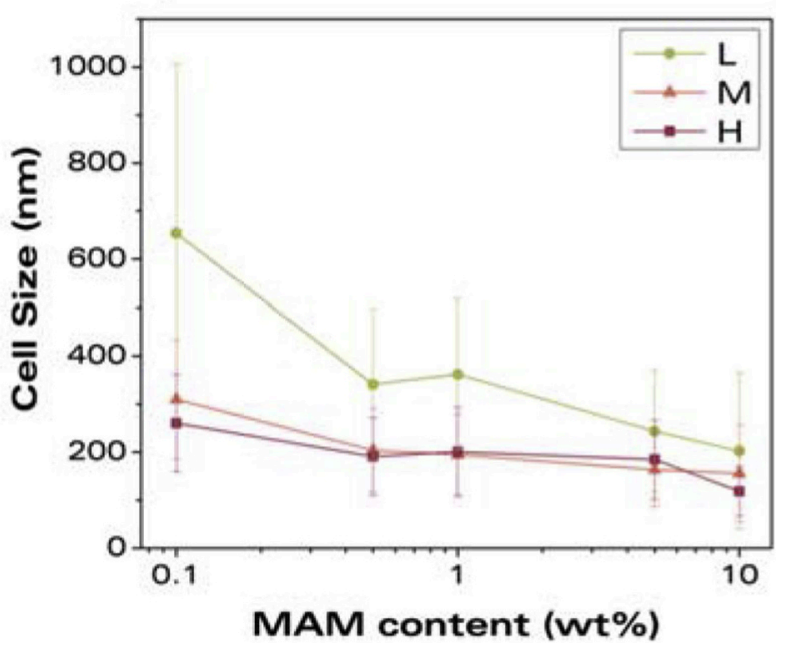

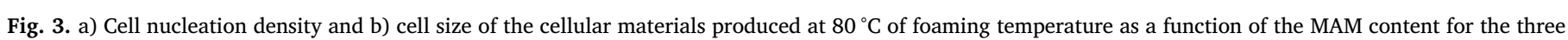
grades of MAM.

MAM contents. As previously mentioned, it is possible that at these low copolymer contents a part of MAM might be dispersed in the PMMA without forming a micelle. As the PBA is $\mathrm{CO}_{2}$-philic, the Gibbs energy of nucleus formation is reduced in these molecules compared to the pure PMMA. Also, the surface tension in the PBA phase is smaller than that of the PMMA [30]. Therefore, nucleation can take place in the small MAM-rich regions. Colton et al. reported a similar idea for a zinc stearate-polystyrene system, in which nucleation below the solubility limit was even higher than after the formation of the zinc stearate particles [40]. We propose that nucleation in these PMMA/MAM systems with low MAM contents is a consequence of two processes: nucleation in the micelles and in the MAM-rich regions, which are too small to form a micelle. We have analyzed in more detail this nucleation effect by studying the effect of the saturation pressure in the Supplementary Information.

On the other hand, cell size presents the opposite behavior (Fig. 3b): lower MAM contents lead to higher cell sizes. All the blends show cell sizes in the range $340-120 \mathrm{~nm}$, except for the blend $0.1 \%-\mathrm{L}$, which shows a sub-micrometric cellular structure. As far as the authors know, this is the first time PMMA/MAM nanocellular polymers have been

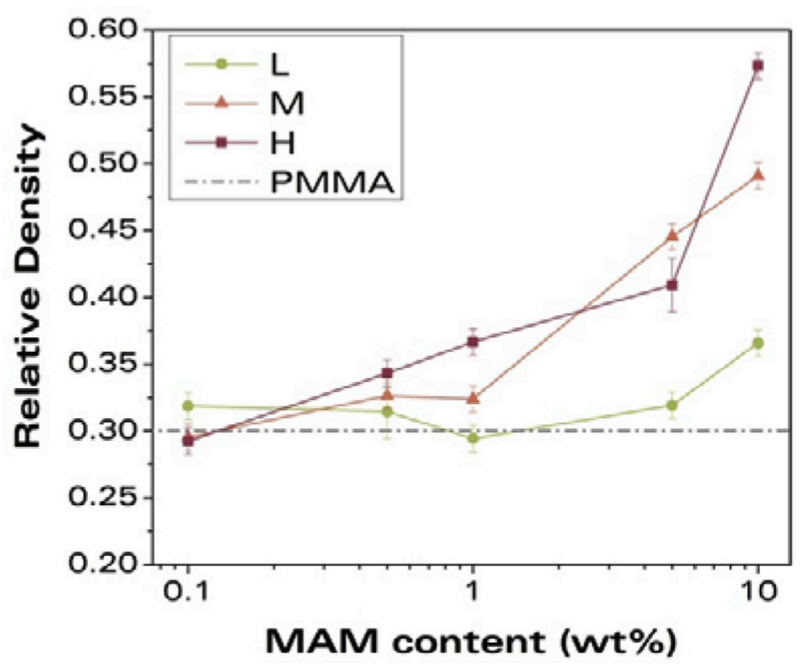

Fig. 4. Relative density of the cellular materials produced at $80{ }^{\circ} \mathrm{C}$ of foaming temperature as a function of the MAM content for the three grades of MAM. Pure PMMA (continuous dashed line) was added as a reference. produced using such low copolymer contents. In particular, a cell size of $260 \mathrm{~nm}$ combined with a relative density of 0.29 has been obtained for the material $0.1 \%-\mathrm{H}$. The cell size is a consequence of the micelle density: the smaller the number of micelles, the greater the distance among them and therefore more space for the micelles to grow (higher cell size) [31]. The cell size distribution of these samples can be found in the Supplementary Information (Figure S6).

The relative density of these cellular materials is shown in Fig. 4. Relative densities between 0.57 and 0.29 were obtained. A reduction in the MAM copolymer content causes a reduction of the relative density. This reduction is more relevant for the copolymers $\mathrm{M}$ and $\mathrm{H}$. For instance, for the copolymer $\mathrm{H}$, a reduction in the MAM content from $10 \mathrm{wt} \%$ to $0.1 \mathrm{wt} \%$ (100 times reduction) yields to a decrease in density of a $49 \%$ (from 0.57 to 0.29 ). The pure PMMA processed under the same conditions gives a microcellular material with a relative density of 0.3 [31] (dashed line in Fig. 4), so when the copolymer content is reduced the density approaches that obtained with the pure polymer. This decreasing trend of the relative density can be related to the cell size: the lower the MAM content, the greater the cell size and thus the smaller the density. A small change in the cell size can become a great difference in density due to the high density of cells in these materials. For instance, a change from 120 to $180 \mathrm{~nm}$ leads to a reduction of the density from 0.57 to 0.40 when the MAM type $\mathrm{H}$ is reduced from $10 \mathrm{wt}$ $\%$ to $5 \mathrm{wt} \%$.

\subsection{Effect of the foaming temperature on the cellular structure}

To further reduce the relative densities obtained so far, two additional foaming temperatures were tested, 60 and $100^{\circ} \mathrm{C}$, whereas the rest of the processing parameters remained the same. Only those blends based on the copolymer with medium molecular weight, $\mathrm{M}$, were used in this section to make the study clearer. Nonetheless, similar results and trends were observed for the other materials.

SEM micrographs of some of these materials are shown in Fig. 5. The blend $10 \%-\mathrm{M}$ present a very similar cellular structure at 60 and $100{ }^{\circ} \mathrm{C}$, but an increase in the cell size is observed when foaming temperature increases for $0.1 \%-\mathrm{M}$ and $1 \%-\mathrm{M}$.

Cell nucleation density is not affected by the foaming temperature regardless of the MAM content (Fig. 6a). In Fig. $6 \mathrm{~b}$ and in the cell size distributions (Figure S7, see Supplementary Information) it is observed that the blends with high MAM content (5\%-M and 10\%-M) show constant cell size and narrow cell size distribution for the different temperatures. The blends with medium content (say 0.5\%-M and 1\%- 


\section{$0.1 \%-M$}
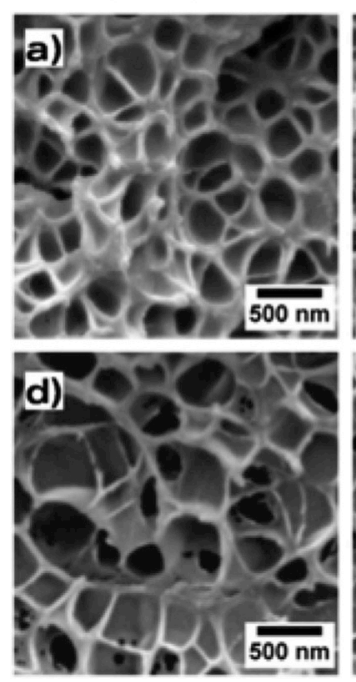

$1 \%-M$
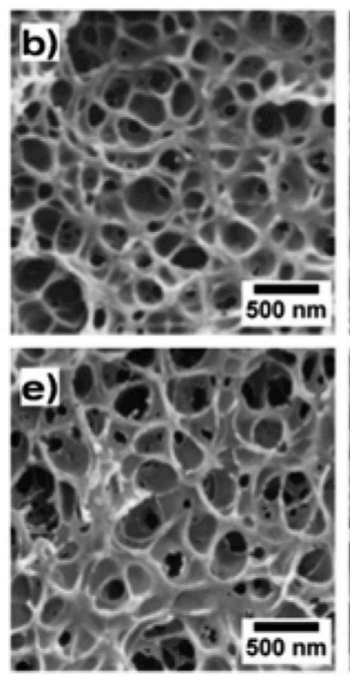

$10 \%-M$

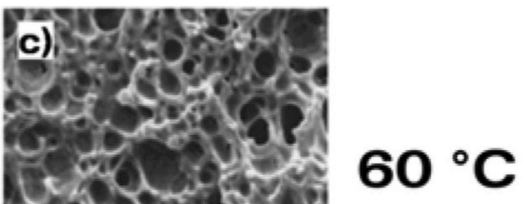

\section{$100^{\circ} \mathrm{C}$}

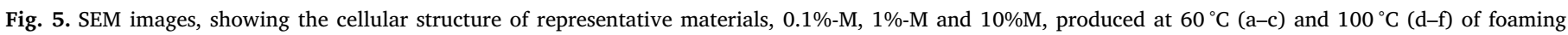
temperature.

M) also show constant average cell size with temperature, but the cell size distribution becomes wider (also observed in Fig. 5e). Finally, the blend $0.1 \%-\mathrm{M}$ presents an increase in the cell size for higher foaming temperatures. We can conclude that in the systems presenting only micelles in a high density the increase of foaming temperature does not allow further cell growth, because the cell growth is limited by the distance between the micelles [31]. However, in systems with fewer micelles (separated greater distances) such as $0.5 \%-\mathrm{M}$ and $1 \%-\mathrm{M}$, cells can grow slightly more, causing a wider cell size distribution when temperature increases. In addition, as there might be some nucleation in dispersed MAM groups of molecules, those nuclei have not any restriction to grow. Accordingly, in the system without micelles (0.1\%-M) there is no restriction at all, and foaming temperature enhances cell growth.

All the cell sizes reported in Fig. $6 \mathrm{~b}$ are smaller than $360 \mathrm{~nm}$, that is, for contents from $0.1 \mathrm{wt} \%$ to $10 \mathrm{wt} \%$ of MAM, and for foaming temperatures varying between 60 and $100{ }^{\circ} \mathrm{C}$, nanocellular polymers can be produced.

Fig. 7 shows the evolution of the relative density as a function of the foaming temperature for the blends with different contents of MAM (type M). The relative density of the pure polymer produced under the same conditions was also included as reference. High and low copolymer contents behave differently. For high MAM contents ( $5 \mathrm{wt} \%$ and $10 \mathrm{wt} \%$ ) foaming temperature does not produce a significant effect on the density. However, for copolymer contents of $1 \mathrm{wt} \%$ or less, an increase in the foaming temperature leads to a reduction in the relative density. The lowest MAM content provides the lowest relative density: at $100{ }^{\circ} \mathrm{C}$ the blend $0.1 \%-\mathrm{M}$ presents a relative density of 0.23 .

As the cell nucleation density was observed to be independent on the foaming temperature, the growth of the cells must be taken into account to explain the trends observed for the relative density. At high MAM contents ( $5 \mathrm{wt} \%$ and $10 \mathrm{wt} \%$ ), it seems that micelles are limiting the growth because of the organization of the copolymer molecules around the micelle. This limitation is geometric, as the spherical organization in the micelle induces cell growth with the same geometry. According to previous results, we hypothesized that in these systems cells grow until a certain cell wall thickness is reached (around $25 \mathrm{~nm}$ ) [31]. Once this thickness is reached the cells cannot grow any further, so foaming temperature does not induce any change in relative density (Table 4 and Fig. 7). For $1 \mathrm{wt} \%$ and $0.5 \mathrm{wt} \%$, the behavior is different. a)

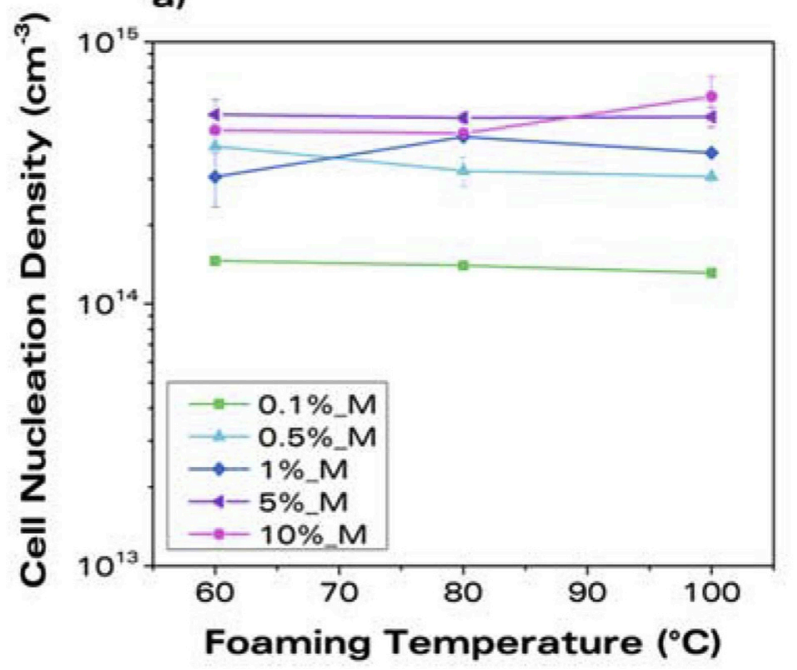

b)

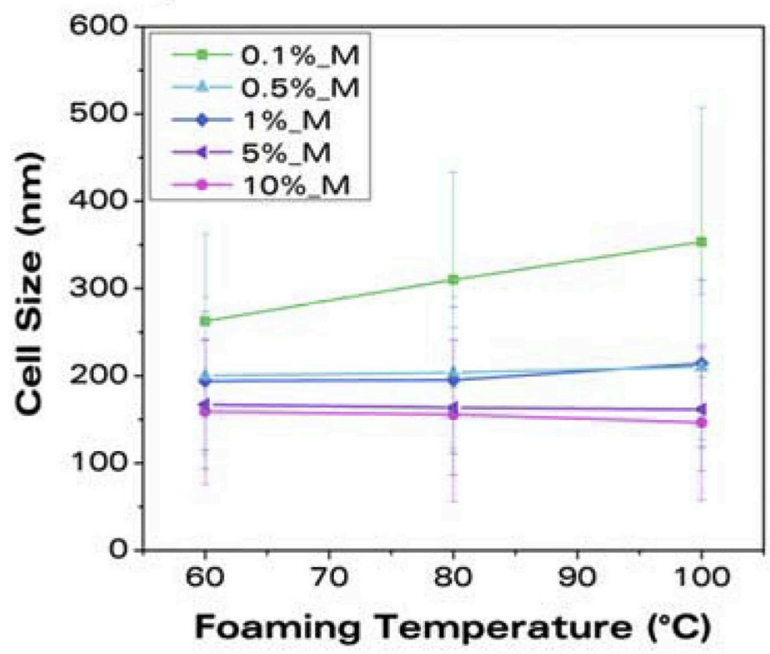

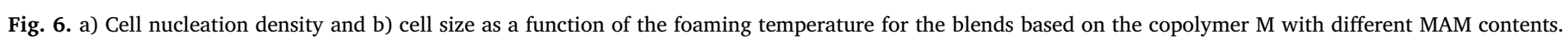




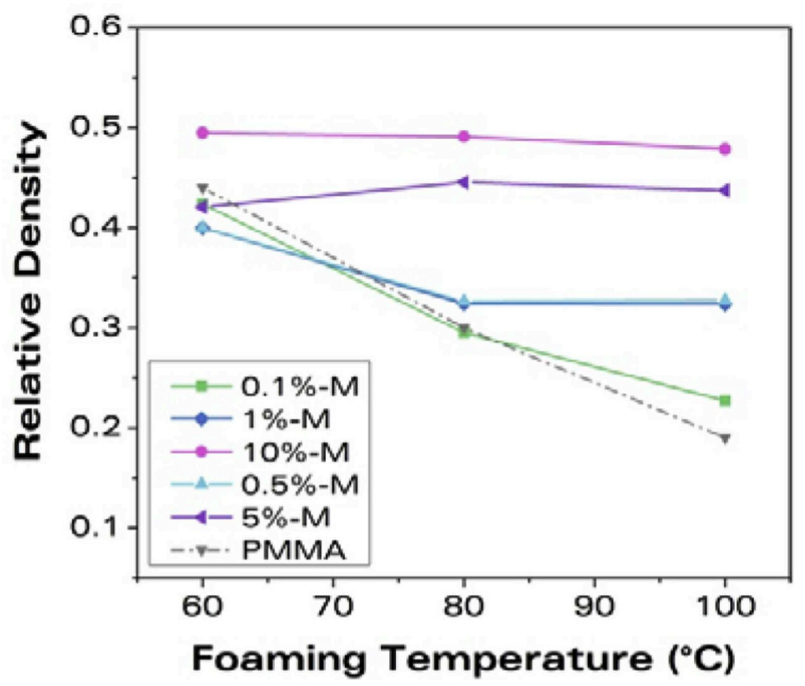

Fig. 7. Relative density as a function of the foaming temperature for the blends based on the copolymer M with different MAM contents.

Table 4

Relative density, cell wall thickness and fraction of mass in the struts for the blends $0.1 \%-\mathrm{M}, 1 \%-\mathrm{M}$ and 10\%-M foamed at different temperatures.

\begin{tabular}{lllll}
\hline Sample ID & $\begin{array}{l}\text { Foaming } \\
\text { Temperature }\left({ }^{\circ} \mathrm{C}\right)\end{array}$ & $\begin{array}{l}\text { Relative } \\
\text { Density }\end{array}$ & $\begin{array}{l}\text { Cell Wall } \\
\text { Thickness } \\
(\mathrm{nm})\end{array}$ & $\begin{array}{l}\text { Fraction of mass } \\
\text { in the struts }\end{array}$ \\
\hline $0.1 \%-\mathrm{M}$ & 60 & 0.42 & $38 \pm 11$ & $0.70 \pm 0.04$ \\
$0.1 \%-\mathrm{M}$ & 80 & 0.30 & $37 \pm 9$ & $0.52 \pm 0.02$ \\
$0.1 \%-\mathrm{M}$ & 100 & 0.23 & $34 \pm 11$ & $0.42 \pm 0.00$ \\
$1 \%-\mathrm{M}$ & 60 & 0.40 & $32 \pm 9$ & $0.72 \pm 0.04$ \\
$1 \%-\mathrm{M}$ & 80 & 0.32 & $29 \pm 8$ & $0.64 \pm 0.01$ \\
$1 \%-\mathrm{M}$ & 100 & 0.32 & $27 \pm 9$ & $0.61 \pm 0.02$ \\
$10 \%-\mathrm{M}$ & 60 & 0.49 & $24 \pm 6$ & $0.71 \pm 0.04$ \\
$10 \%-\mathrm{M}$ & 80 & 0.49 & $25 \pm 6$ & $0.72 \pm 0.04$ \\
$10 \%-\mathrm{M}$ & 100 & 0.48 & $26 \pm 7$ & $0.68 \pm 0.03$ \\
\hline
\end{tabular}

An increase of the foaming temperature from 60 to $100{ }^{\circ} \mathrm{C}$ induces a reduction of the density. However, cell nucleation density is constant, and cell sizes vary only slightly (from 194 to $210 \mathrm{~nm}$ for $0.5 \%-\mathrm{M}$ ) (Fig. 6). Cell wall thickness is also constant, around $30 \mathrm{~nm}$ (Table 4). The reduction of the relative density must be understood by taking into account the reduction of the fraction of mass in the struts (Table 4). This result is even more evident for the blend 0.1\%-M: relative density decreases as a consequence of a reduction of the mass in the struts, as already seen for nanocellular PMMA [19]. Fig. 8 shows local thickness analysis of the materials based on $0.1 \%-\mathrm{M}$ foamed at different temperatures, showing the reduction of mass in the struts. In Fig. 9, the fraction of mass in the struts is represented as a function of the relative density. It is observed that lower relative densities imply smaller

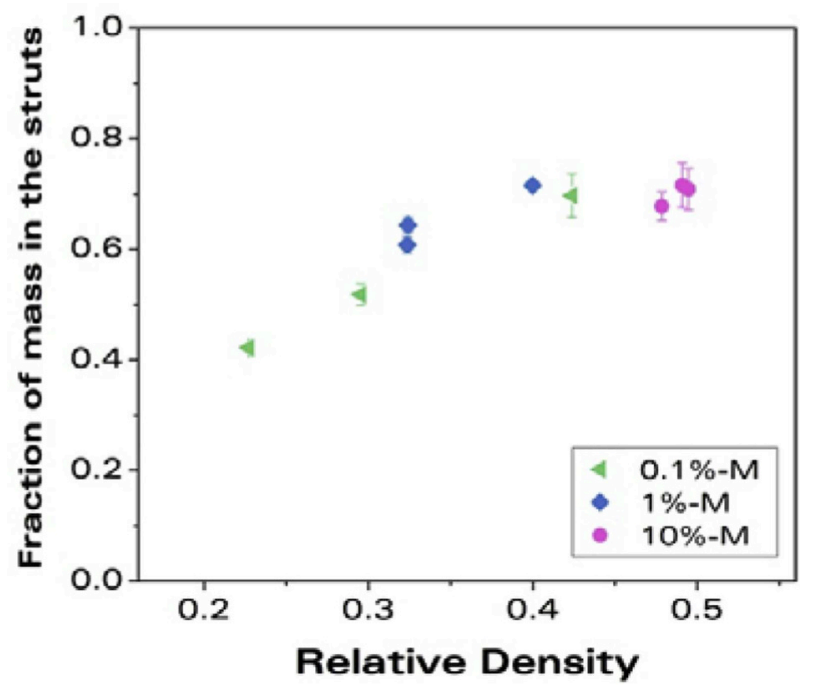

Fig. 9. Fraction of mass in the struts as a function of the relative density for the blends $0.1 \%-\mathrm{M}, 1 \%-\mathrm{M}$ and $10 \%-\mathrm{M}$ foamed at different temperatures.

fractions of mass in the struts.

The difference between high and low MAM contents is based on the different nucleation. At high contents, nucleation takes place in the spherical micelles, which limit the growing process [31]. On the other hand, at low contents nucleation also takes place in the MAM-rich regions that are not a micelle. In that case, there is not a limitation of spherical growth due to the organization of the copolymer molecules. Therefore, cells can grow in any shape and adopt polygonal geometries to fill the space. As a consequence, relative density can be reduced by this mechanism of decreasing the polymer mass in the struts.

Therefore, a new strategy to reduce the relative density in PMMA/ MAM systems has been identified. By reducing the amount of block copolymer to contents below the critical micelle concentration, the formation of micelles is avoided, but block copolymer is still present in the blend. As a result, nucleation is enhanced, but the growing of the cells is not limited by the spherical organization induced by the micelles, allowing obtaining reduced relative densities for these very low MAM contents.

Thanks to this strategy, materials with a wide range of relative densities and cell sizes have been produced. All the materials produced in this work are shown in the cell size - relative density map of Fig. 10, including materials produced with the copolymers $\mathrm{L}$ and $\mathrm{H}$ at different foaming temperatures (not discussed in section 2.3). Some materials from the literature are also included as a reference. Lines of constant cell nucleation density, calculated using equation (4) [33], are also included. In addition, a boundary line representing a constant cell wall thickness was plotted. According to equation (5) [41], the cell wall thickness $(\xi)$ is related to the cell size, the relative density, the fraction of mass in the struts $\left(f_{s}\right)$ and $C$ is a constant that depends on the cell
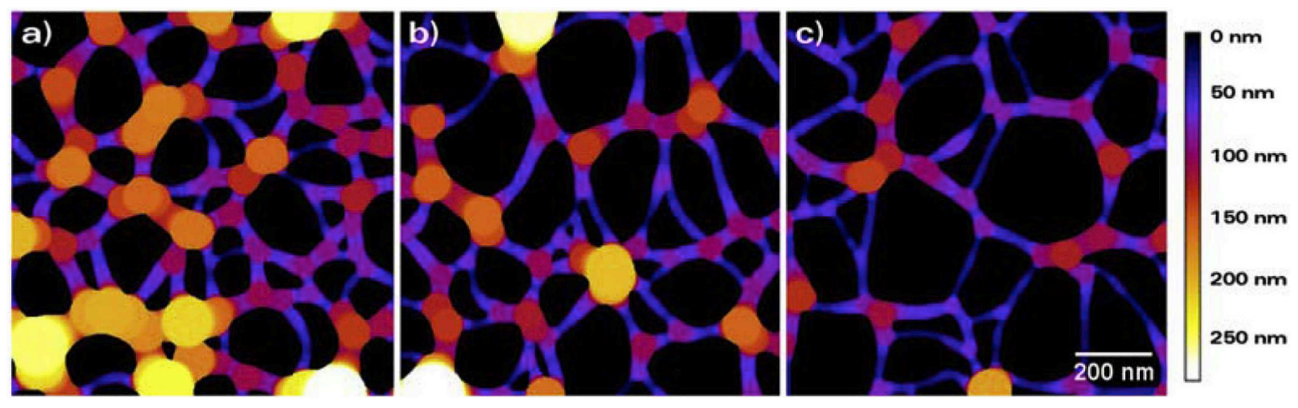

Fig. 8. Local thickness analysis of the materials based on $0.1 \%-\mathrm{M}$ foamed at different temperatures: a) $60^{\circ} \mathrm{C}$, b) $80^{\circ} \mathrm{C}$ and c) $100^{\circ} \mathrm{C}$. 


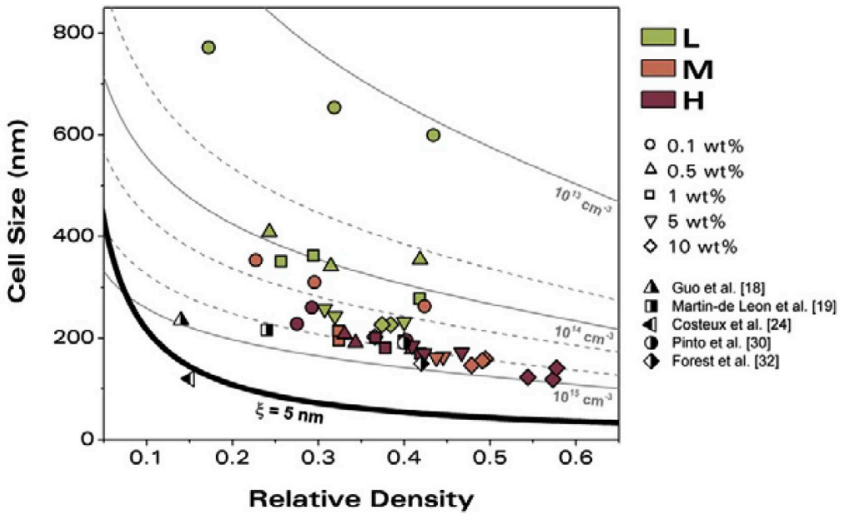

Fig. 10. Cell size - relative density map of all the materials produced in this work and some literature materials. Circles: $0.1 \mathrm{wt} \%$, up triangles: $0.5 \mathrm{wt} \%$, squares: $1 \mathrm{wt} \%$, down triangles: $5 \mathrm{wt} \%$, diamond: $10 \mathrm{wt} \%$. Green: copolymer L, orange: copolymer M, red: copolymer $\mathrm{H}$. Grey curves indicate regions of constant cell nucleation density according to equation (4). The constant thick black line indicates the curve of constant cell wall thickness according to equation (5).

shape. This equation is valid for closed cell cellular materials. For the line in Fig. 10, a fraction of mass in the struts of 0.2 was considered, as this is a typical value for low density cellular materials [41]. For the cell wall thickness, a value of $5 \mathrm{~nm}$ was assumed, a reasonable minimum value for a cell wall formed by aligned polymer chains with a certain width (for instance, the radius of gyration of PMMA was estimated around $4 \mathrm{~nm}$ [42]). Regarding the constant $C$, it takes a value of 3.46 for pentagonal dodecahedrons [43].

$1-\rho_{r}=\frac{\pi \phi^{3}}{6} N_{v}$

$C \xi=\phi\left(1-f_{s}\right) \rho_{r}$

As displayed in Fig. 10, the materials produced in this work cover a wide range of relative densities (ranging from 0.17 to 0.58 ) and cell sizes $(770-120 \mathrm{~nm})$. Also, all the cellular materials plotted in this map, both from this work and from literature, lie above or near the theoretical line of constant cell wall thickness, supporting our hypothesis of the limitation imposed by the minimum cell wall thickness.

According to this idea, the region under the theoretical line of constant cell wall thickness, it is a forbidden region, because materials in that part of the graph will require cell wall thicknesses smaller than $5 \mathrm{~nm}$, so there are some combinations of relative density and cell size that might be impossible. For instance, according to this model and for a PMMA matrix with a minimum cell wall of $5 \mathrm{~nm}$, a closed cell cellular material with a relative density of 0.1 and a cell size of $50 \mathrm{~nm}$ would be unachievable due to geometric limitations.

This is, of course, a very strong hypothesis because up to know there is no definitive evidence of what is the minimum cell wall thickness that could be achieved in these nanocellular polymers. However, it seems reasonable to assume the existence of a limit value of the cell wall thickness, which would depend on the size of the molecules and would be in the range of some nanometers. In the case of open cell cellular materials, it is expectable that the window of achievable materials would be wider.

\section{Conclusions}

In this work, new strategies to obtain low-density nanocellular materials based on PMMA/MAM blends have been explored. First, the influence of the amount of block copolymer was tested by producing blends at five MAM contents (from $0.1 \mathrm{wt} \%$ to $10 \mathrm{wt} \%$ ). Second, the effect of the foaming temperature as a way to reduce the density was investigated. Results show that both strategies, reducing the amount of
MAM and increasing the foaming temperature, promote a reduction of the density in these systems.

The non-equilibrium nanostructuration achieved after the extrusion was dependent on the MAM content. Results show that the lower the MAM content, the smaller the micelle density. This result is understood by taking into consideration two phenomena: the dispersion of the MAM during the extrusion process and the self-assembly of the MAM molecules. During the extrusion process, lower MAM contents are dispersed in smaller domains, leading to lower micelle densities. For very low MAM contents, the micelles were hardly detected, so it was assumed that some MAM should be dispersed in the matrix forming MAMrich regions, but without forming a micelle.

In the analysis of the effect of the MAM content on the cellular materials, a reduction of the relative density was detected when the amount of block copolymer decreases, but also an increase of the cell size. Despite the higher cell sizes obtained at low contents, nanocellular materials (cell size $260 \mathrm{~nm}$ ) with low relative density (0.3) were obtained. At low contents, cell nucleation density was larger than micelle density, so we hypothesized that nucleation could also occur in small MAM-rich regions even though there is no micelle.

On the other hand, the effect of the foaming temperature on the density was analyzed. High and low MAM contents behave very differently. Blends with high MAM contents were not able to expand more when the foaming temperature was increased. As growth may be limited by the organization of the molecules in the micelles, growth would stop once a minimum cell wall thickness is reached. On the other hand, low MAM contents show smaller densities for higher foaming temperatures. As nucleation in these systems takes place partially in MAMrich regions, those cells can grow in any shape, reducing the density. This idea was supported by measuring the fraction of mass in the struts, which is indeed constant for high MAM contents and it reduces with density for low MAM contents. Finally, by applying the strategies identified in this work, a material with a minimum density of 0.23 and $350 \mathrm{~nm}$ of cell size was obtained.

\section{Acknowledgements}

Financial assistance from MINECO, FEDER, UE (MAT2015-69234R) and the Junta de Castile and Leon (VA011U16) are gratefully acknowledged. Financial support from FPU grant FPU14/02050 (V. Bernardo) from the Spanish Ministry of Education, Juan de la CiervaIncorporación grant IJCI-2016-29992 (J. Pinto) from Spanish MINECO, and Junta of Castile and Leon grant of J. Martín-de León are gratefully acknowledged. We also want to thank Arkema for supplying the copolymers used in this research.

\section{Appendix A. Supplementary data}

Supplementary data to this article can be found online at https:// doi.org/10.1016/j.polymer.2018.12.057.

\section{References}

[1] European Commission, Horizon 2020 Work Programme 2018 - 2020: 10. Secure, Clean and Efficient Energy, (2017) https://ec.europa.eu/programmes/ horizon2020/en/h2020-section/secure-clean-and-efficient-energy.

[2] International Energy Agency (IEA), Technology Roadmap, Energy Efficient Building Envelopes, (2013), https://doi.org/10.1007/SpringerReference_7300.

[3] M. Alam, H. Singh, M.C. Limbachiya, Vacuum insulation panels (VIPS) for building construction industry - a review of the contemporary developments and future directions, Appl. Energy 88 (2011) 3592-3602, https://doi.org/10.1016/j.apenergy. 2011.04.040.

[4] B.P. Jelle, Traditional, state-of-the-art and future thermal building insulation materials and solutions - properties, requirements and possibilities, Energy Build. 43 (2011) 2549-2563, https://doi.org/10.1016/j.enbuild.2011.05.015.

[5] B. Notario, J. Pinto, E. Solorzano, J.A. de Saja, M. Dumon, M.A. Rodriguez-Perez, Experimental validation of the Knudsen effect in nanocellular polymeric foams, Polymer 56 (2015) 57-67, https://doi.org/10.1016/j.polymer.2014.10.006.

[6] B. Notario, J. Pinto, M.A. Rodríguez-Perez, Towards a new generation of polymeric 
foams: PMMA nanocellular foams with enhanced physical properties, Polymer 63 (2015) 116-126, https://doi.org/10.1016/j.polymer.2015.03.003.

[7] B. Notario, J. Pinto, M.A. Rodriguez-Perez, Nanoporous polymeric materials : a new class of materials with enhanced properties, Prog. Polym. Sci. (2016) 78-79, https://doi.org/10.1016/j.pmatsci.2016.02.002 93-139.

[8] J. Pinto, B. Notario, R. Verdejo, M. Dumon, S. Costeux, M.A. Rodriguez-perez, Molecular confinement of solid and gaseous phases of self-standing bulk nanoporous polymers inducing enhanced and unexpected physical properties, Polymer 113 (2017) 27-33, https://doi.org/10.1016/j.polymer.2017.02.046.

[9] B. Notario, A. Ballesteros, J. Pinto, M.A. Rodriguez-Perez, P.M.M.A. Nanoporous, A novel system with different acoustic properties, Mater. Lett. 168 (2016) 76-79, https://doi.org/10.1016/j.matlet.2016.01.037.

[10] S. Perez-Tamarit, B. Notario, E. Solorzano, M.A. Rodriguez-Perez, Light transmission in nanocellular polymers: are semi-transparent cellular polymers possible? Mater. Lett. 210 (2017) 39-41, https://doi.org/10.1016/j.matlet.2017.08.109.

[11] G. Wang, J. Zhao, L.H. Mark, G. Wang, K. Yu, C. Wang, C.B. Park, G. Zhao, Ultratough and super thermal-insulation nanocellular PMMA/TPU, Chem. Eng. J. 325 (2017) 632-646, https://doi.org/10.1016/j.cej.2017.05.116.

[12] C. Forest, P. Chaumont, P. Cassagnau, B. Swoboda, P. Sonntag, Polymer nano-foams for insulating applications prepared from CO 2 foaming, Prog. Polym. Sci. 41 (2015) 122-145, https://doi.org/10.1016/j.progpolymsci.2014.07.001.

[13] Z. Li, C. Zhu, X. Zhao, A theoretical and numerical study on the gas-contributed thermal conductivity in aerogel, Int. J. Heat Mass Tran. 108 (2017) 1982-1990.

[14] V. Bernardo, J. Martín-de Leon, M.A. Rodriguez-Perez, Production and characterization of nanocellular polyphenylsulfone foams, Mater. Lett. 178 (2016) 155-158, https://doi.org/10.1016/j.matlet.2016.05.002.

[15] H. Guo, V. Kumar, Some thermodynamic and kinetic low-temperature properties of the PC-CO2 system and morphological characteristics of solid-state PC nanofoams produced with liquid CO2, Polymer 56 (2015) 46-56, https://doi.org/10.1016/j. polymer.2014.09.061.

[16] D. Miller, P. Chatchaisucha, V. Kumar, Microcellular and nanocellular solid-state polyetherimide ( PEI ) foams using sub-critical carbon dioxide I . Processing and structure, Polymer 50 (2009) 5576-5584, https://doi.org/10.1016/j.polymer. 2009.09.020.

[17] H. Guo, A. Nicolae, V. Kumar, Solid-State microcellular and nanocellular polysulfone foams, J. Polym. Sci., Part B: Polym. Phys. 53 (2015) 975-985, https://doi. org/10.1002/polb.23719.

[18] H. Guo, A. Nicolae, V. Kumar, Solid-state poly(methyl methacrylate) (PMMA) nanofoams. Part II: low-temperature solid-state process space using $\mathrm{CO} 2$ and the resulting morphologies, Polymer 70 (2015) 231-241, https://doi.org/10.1016/j. polymer.2015.06.031.

[19] J. Martin de-Leon, V. Bernardo, M.A. Rodriguez-Perez, Low density nanocellular polymers based on PMMA produced by gas dissolution Foaming: fabrication and cellular structure characterization, Polymers 8 (2016) 1-16, https://doi.org/10. 3390/polym8070265.

[20] S. Costeux, I. Khan, S.P. Bunker, H.K. Jeon, Experimental study and modeling of nanofoams formation from single phase acrylic copolymers, J. Cell. Plast. 51 (2015) 197-221, https://doi.org/10.1177/0021955X14531972.

[21] H. Guo, A. Nicolae, V. Kumar, Fabrication of high temperature polyphenylsulfone nanofoams using high pressure liquid carbon dioxide, Cell. Polym. 35 (2015) 2016.

[22] J. Pinto, D. Morselli, V. Bernardo, B. Notario, D. Fragouli, M.A. Rodriguez-Perez, A. Athanassiou, Nanoporous PMMA foams with templated pore size obtained by localized in situ synthesis of nanoparticles and CO 2 foaming, Polymer 124 (2017) 176-185, https://doi.org/10.1016/j.polymer.2017.07.067.

[23] L. Urbanczyk, C. Calberg, C. Detrembleur, C. Jérôme, M. Alexandre, Batch foaming of SAN/clay nanocomposites with scCO 2 : a very tunable way of controlling the cellular morphology, Polymer 51 (2010) 3520-3531, https://doi.org/10.1016/j. polymer.2010.05.037.

[24] S. Costeux, L. Zhu, Low density thermoplastic nanofoams nucleated by nanoparticles, Polymer 54 (2013) 2785-2795, https://doi.org/10.1016/j.polymer.2013.
03.052.

[25] V. Bernardo, J. Martin-de León, E. Laguna-Gutiérrez, M.Á. Rodríguez-Pérez, PMMAsepiolite nanocomposites as new promising materials for the production of nanocellular polymers, Eur. Polym. J. 96 (2017) 10-26, https://doi.org/10.1016/j. eurpolymj.2017.09.002.

[26] J. Pinto, M. Dumon, M.A. Rodriguez-Perez, Nanoporous polymer foams from nanostructured polymer blends: preparation, characterization, and properties, in: P. Visakh, G. Markovic, D. Pasquini (Eds.), Recent Dev. Polym. Macro, Micro Nano Blends, Woodhead Publishing in Materials, 2016, pp. 237-288.

[27] S. Costeux, CO2-blown nanocellular foams, J. Appl. Polym. Sci. 131 (2014), https:// doi.org/10.1002/app.41293 41293(1)-41293(16).

[28] J. Pinto, M. Dumon, M.A. Rodriguez-Perez, R. Garcia, C. Dietz, Block copolymers self-assembly allows obtaining tunable micro or nanoporous membranes or depth filters based on PMMA; fabrication method and nanostructures, J. Phys. Chem. C 118 (2014) 4656-4663, https://doi.org/10.1021/jp409803u.

[29] J. Pinto, J.A. Reglero-ruiz, M. Dumon, M.A. Rodriguez-Perez, Temperature influence and $\mathrm{CO} 2$ transport in foaming processes of poly (methyl methacrylate)- block copolymer nanocellular and microcellular foams, J. Supercrit. Fluids 94 (2014) 198-205, https://doi.org/10.1016/j.supflu.2014.07.021.

[30] J. Pinto, M. Dumon, M. Pedros, J. Reglero, M.A. Rodriguez-Perez, Nanocellular CO2 foaming of PMMA assisted by block copolymer nanostructuration, Chem. Eng. J. 243 (2014) 428-435, https://doi.org/10.1016/j.cej.2014.01.021.

[31] V. Bernardo, J. Martin-de Leon, E. Laguna-Gutierrez, T. Catelani, J. Pinto, A. Athanassiou, M.A. Rodriguez-Perez, Understanding the role of MAM molecular weight on the production of PMMA/MAM nanocellular polymers, Polymer 153 (2018) 262-270, https://doi.org/10.1016/j.polymer.2018.08.022.

[32] C. Forest, P. Chaumont, P. Cassagnau, B. Swoboda, P. Sonntag, CO2 nano-foaming of nanostructured PMMA, Polymer 58 (2015) 76-87, https://doi.org/10.1016/j. polymer.2014.12.048.

[33] V. Kumar, N.P. Suh, A process for making microcellular parts, Polym. Eng. Sci. 30 (1990) 1323-1329.

[34] P. Spitael, C.W. Macosko, R.B. Mcclurg, Block copolymer micelles for nucleation of microcellular thermoplastic foams, Macromolecules 37 (2004) 6874-6882.

[35] J. Pinto, E. Solorzano, M.A. Rodriguez-perez, J.A. De Saja, Characterization of the cellular structure based on user-interactive image analysis procedures, J. Cell. Plast. 49 (2013) 555-575, https://doi.org/10.1177/0021955X13503847.

[36] V. Kumar, Process Synthesis for Manufacturing Microcellular Thermoplastic Parts, Massachusetts Institute of Technology, 1988.

[37] R.G. Alargova, I.I. Kochijashky, M.L. Sierra, R. Zana, Micelle aggregation numbers of surfactants in aqueous Solutions : a comparison between the results from steadystate and time-resolved fluorescence quenching, Langmuir 7463 (1998) 5412-5418, https://doi.org/10.1021/la980565x.

[38] S. Siripurapu, J.M. Desimone, S.A. Khan, R.J. Spontak, N. Carolina, N. Carolina, Controlled foaming of polymer films through restricted surface diffusion and the addition of nanosilica particles or CO2-philic surfactants, Macromolecules 38 (2005) 2271-2280.

[39] M.D. Whitmore, T.W. Smith, Swelling of copolymer micelles by added homopolymer, Macromolecules 27 (1994) 4673-4683, https://doi.org/10.1021/ ma00095a006.

[40] J.S. Colton, N.P. Suh, The nucleation of microcellular thermoplastic foam with additives: Part I: theoretical considerations, Polym. Eng. Sci. 27 (1987) 485-492.

[41] L.J. Gibson, M. Ashby, Cellular Solids: Structure and Properties, second ed., Cambridge University Press, 1997.

[42] D.Q. Zou, H. Yoshida, Size effect of silica nanoparticles on thermal decomposition of PMMA, J. Ann. Therm. Anal. Calorim. 99 (2010) 21-26, https://doi.org/10. 1007/s10973-009-0531-4.

[43] O.A. Almanza, J.A. de Saja, M.A. Rodriguez-Perez, Prediction of the radiation term in the thermal conductivity of crosslinked closed cell polyolefin foams, J. Polym. Sci., Part B: Polym. Phys. 38 (2000) 993-1004, https://doi.org/10.1002/(SICI) 1099-0488(20000401)38:7 < 993::AID-POLB10 > 3.0.CO;2-J. 